\title{
Evaluation of the Efficacy of Adrenaline Injection Versus Argon Plasma Coagulation Either Alone or Combined in Controlling Acute Bleeding Peptic Ulcer
}

\author{
Amr Talaat EL Hawary ${ }^{1}$ and Emad A Moustafa ${ }^{2}$ \\ ${ }^{I}$ Internal Medicine Department, Hepatogastroenterology Division, Zagazig University, Egypt \\ ${ }^{2}$ Tropical Medicine Department, Zagazig University, Egypt
}

Corresponding Author: Amr Talaat El-Hawary

E mail:

dramrelhawary@yaho o.com

Mobil: +201003725577

Key words:

Adrenaline; Argon plasma coagulation; Bleeding peptic ulcer
Background and study aim: Evaluating the sequale and outcomes of managing acute bleeding peptic ulcer by using either diluted adrenaline injection or argon plasma coagulation alone versus using both modalities.

Materials and Methods: This study was performed over a 1.5-year period from January 2016 to June 2017. Acute bleeding peptic ulcer patients were assigned randomly to either treatment with diluted adrenaline injection (group I), or with an APC application (group II) or treated using both (group III). All groups were compared regarding the rate of initial hemostasis, rate of recurrent bleeding, successful definitive hemostasis, need for emergency surgery and bleeding-related deaths.

Results: In total, 60 patients with acute bleeding peptic ulcer were enrolled randomly in three groups; group I included 20 patients who were treated with

\section{INTRODUCTION}

Upper gastrointestinal bleeding originates proximal to the ligament of Treitz in the duodenum. Its main causes are divided into either variceal or non-variceal and although there are various sources for non-variceal upper GI bleeding (as severe esophagitis, gastroduodenal erosions, MalloryWeiss tears, and vascular malformations), bleeding peptic ulcer remains the most common cause. [1]

Acute bleeding peptic ulcer presented with hematemesis, melena, or both, has significant associated morbidity or mortality [2]. Probably due to the effect of using aspirin or nonsteroidal antiinflammatory drugs and the comorbidities in elderly populations in numerous counties[3]. endoscopic adrenaline injection, group II included 20 patients and were exposed to Argon plasma coagulation in sessions and group III included 20 patients who were subjected to both modalities. Patients were followed up in ICU and received PPI IV infusion, Endoscopy was performed one week after initial hemostasis, a second look endoscopy was performed in patients who showed recurrent bleeding. Results revealed significant $(\mathrm{p}<0.05)$ superior efficacy of both modalities when used together (group III) compared with using either alone as regard inducing initial and permanent hemostasis, controlling rebleeding and minimizing hospital admission days.

Conclusion: Using both endoscopic adrenaline injection and argon plasma coagulation as a combined therapy is highly efficacious in managing acute bleeding peptic ulcer than using each alone.

Many scoring systems have been used to stratify risk in upper GI bleeding. The most widely used are the Rockall scores (both pre- and post-endoscopy) and the Glasgow-Blatchford score (GBS)[4], the Rockall scores assess mortality risk, but were never designed directly as decision tools, but that the GBS was designed to predict cases not needing intervention (therapeutic endoscopy or blood transfusion).[5]

Stigmata of recent hemorrhage was defined according to the Forrest classification as follows (Forrest Iaspurting bleeding, Forrest Ib- oozing bleeding, Forrest IIa- non-bleeding visible vessel, Forrest IIb- adherent clot, Forrest IIc- hematin on ulcer base, Forrest III- clean ulcer base) [6]. 
The therapeutic role of pharmacologic and endoscopic management in controlling bleeding peptic ulcer is continually evaluated to assess and identify the best modality [7].

Endoscopic hemostasis for bleeding peptic ulcer achieves better therapeutic results when compared with pharmacologic or surgical treatment [2].

Various endoscopic modalities have been used, including injection therapy with diluted epinephrine, various sclerosants, and distilled water, hemostatic clipping, and thermocoagulation with heat probe and argon plasma coagulation [APC] [8], hemostatic powders and over-the-scope clips can be used when other methods have failed [9].

Because of its low-cost endoscopic injection of diluted epinephrine has become a commonly used hemostatic method for bleeding peptic ulcers by inducing vasopressor and tamponading effects but with the potential risk of systemic absorption and subsequent hypertensive crisis or arrhythmia [2].

Argon plasma coagulation (APC) is an electrosurgical technique for the management of bleeding and the devitalization of tissue abnormalities. It works by achieving a noncontact thermal coagulation in which highfrequency current is applied to the target tissue through an argon plasma jet creating effective hemostasis and a homogenous surface coagulation with a limited penetration depth [10].

The aim of this study is to evaluate the efficacy of endoscopic local adrenaline injection versus argon plasma coagulation in achieving a significant hemostatic effect in bleeding peptic ulcer.

\section{MATERIALS AND METHODS}

\section{Patient selection}

This study was conducted at Internal Medicine and Tropical Medicine departments, Zagazig University Hospital, Egypt, a tertiary referral center. Over a 1.5 year period from January 2016 to June 2017, 110 patients with bleeding peptic ulcer were admitted to the gastrointestinal emergency unit,50 patients were excluded and 60 patients with stigmata of peptic ulcer bleeding ,fulfilling the inclusion criteria were enrolled.

\section{Study design and method of randomization}

This prospective randomized comparative study was performed by randomly assigning patients to receive Adrenaline Injection $(n=20)$ or Argon plasma coagulation $(n=20)$ or both $(n=20)$.
Patients in whom treatment or retreatment was unsuccessful underwent emergency surgery.

Randomization was performed at the time of endoscopy by an independent physician using a computer-based randomization list.

\section{Consent}

Possible complications of endoscopic treatment were discussed with the patients and their relatives and written informed consent was obtained before trial entry.

\section{Inclusion criteria:}

Included age $>12$ years with acute, highly risky peptic ulcer bleeding, presented with hematemesis and/or melena.

High-risk bleeding ulcers were determined by having stigmata of a bleeding visible vessel (spurting or oozing), a nonbleeding visible vessel (raised red, blue or pale vessel protruding from the ulcer bed without active bleeding), or an adherent clot covering the ulcer site and resisting endoscopic wash.

\section{Exclusion criteria:}

Patients were excluded from the study if they were having a platelet count of less than 70,000, an international normalized ratio of greater than 2 , gastric malignancy, varices multiple bleeding sites, anticoagulant users, pregnancy, and refusal to participate.

\section{History and thorough clinical examination}

All patients were reviewed for the history of nonsteroidal anti-inflammatory drugs, smoking, previous peptic ulcer disease or upper gastrointestinal bleeding).

The clinical characteristics (age, sex, hemodynamic stability and associated comorbid diseases were also recorded.

\section{Biochemical measurements}

CBC, iron, ferritin, Coombs test, reticulocytes, liver function and kidney functions PT and INR
Abdominal ultrasonography
All patients were examined using a real-time grayscale device with a transducer having a frequency of $3.5 \mathrm{MHz}$. the following were noted: Peritoneal free fluid collection, signs of portal hypertension, liver and kidney status
Abdominal plain X-ray: to exclude perforated viscus.

\section{Upper gastrointestinal endoscopy:}
All patients with signs of upper gastrointestinal bleeding underwent endoscopy within $12 \mathrm{~h}$ of 
admission using a video endoscopic system (Pentax EPM-3500) with sedation using intravenous midazolam in a titrated dose up to $0.1 \mathrm{mg} / \mathrm{kg}$ (510mg).

Patients were included if endoscopy showed a gastric or duodenal ulcer with an actively bleeding vessel (spurting or oozing), a nonbleeding visible vessel or an adherent clot.

\section{Adrenaline injection:}

For the group, I patients: Adrenaline $(1: 10,000$ dilution) in $0.5 \mathrm{~mL}$ or $1 \mathrm{~mL}$ doses were injected through multiple punctures into and around the bleeding site, with at least $7 \mathrm{~mL}$ and maximum $15 \mathrm{ml}$ being injected.

\section{Argon plasma coagulation:}

Group II patients were treated with argon plasma coagulation. The APC equipment consisted of an APC probe (lumen $1.5 \mathrm{~mm}$, outer diameter $2.0 \mathrm{~mm}$ ) advanced from the end of the working therapeutic accessory channel of the endoscope, a gas source, and a high-frequency generator. The argon gas flow was set at $2.5 \mathrm{~L} / \mathrm{min}$. The electrical power output was adjusted to $50-80 \mathrm{~W}$ which was safe in relation to the local risk of perforation.

APC was applied to the area of the visible vessel, ooze, spurter for about 1-3 seconds, with the approximately $5 \mathrm{~mm}$ distance between APC probe and the lesion.

The endpoint of successful endoscopic therapy was the production of a white coagulum which limits the depth of coagulation.

Suction was applied to remove smoke and prevent overinflation of the gastrointestinal tract.

\section{Both adrenaline injection and argon plasma coagulation: \\ For group III patients both modalities were used starting with diluted adrenaline injection in and around the ulcer site followed by argon plasma coagulation application.}

Initial hemostasis was determined by the absence of endoscopic evidence of bleeding during $5 \mathrm{~min}$ of observation after the procedure used.

In case of recurrent bleeding, including recurrent hematemesis, persistent melena, hemodynamic instability (pulse rate greater than $110 / \mathrm{min}$, or decrease in systolic blood pressure more than 30 $\mathrm{mmHg}$ ) or drop in hemoglobin of at least $2 \mathrm{~g} / \mathrm{L}$, a second look endoscopy was performed using the same endoscopic hemostatic modality.

\section{Follow up of patients:}

Patients were followed up in ICU and all received PPI IV infusion pantoprazole $(8 \mathrm{mg} / \mathrm{h})$ for one day, started on arrival to the hospital before endoscopic intervention and subsequently, IV PPI $40 \mathrm{mg} / 12 \mathrm{~h}$ for $72 \mathrm{~h}$ was started.

Endoscopy was performed one week after initial hemostasis,

Successful permanent hemostasis was achieved as an endpoint by the absence of recurrent bleeding during a 1 month period after endoscopic hemostasis.

Primary end point was achieved by successful hemostasis from the ulcer post procedural and/or stoppage of hematemesis and melena after the procedure.

Secondary end point was the occurrence of rebleeding within 3 days after the procedure or occurrence of complications.

Aspects of comparison between the three groups included the following:

The rate of initial hemostasis, the rate of recurrent bleeding, successful definitive permanent hemostasis, the need for emergency surgery and bleeding-related deaths.

\section{Sample Size Calculation and Statistical Analysis}

It was estimated that a sample size of at least 60 patients, 20 in each group were required to achieve a statistical power of $80 \%$ with a type I error of 0.05 .

All data were analyzed using SPSS 20.0 for Windows (SPSS Inc., Chicago, Illinois, USA), MedCalc Statistical Software version 15.8 (MedCalc Software bvba, Ostend, Belgium; https://www.medcalc.org; 2015).

Continuous variables were expressed as the mean $\pm \mathrm{SD}$, median and (Range) while the categorical variables were expressed as a number (percentage).

All normally-distributed data were analyzed using Independent Student $t(t)$ test between two independent groups. Data found to be nonnormally distributed were analyzed using the Mann-Whitney U (MW) test.

Percent of categorical variables were compared using the Chi-square $(\chi 2)$ test.

$\mathrm{p}<0.05$ was considered statistically significant (S) and $\mathrm{p} \geq 0.05$ was considered non statistically significant (NS). 


\section{RESULTS}

Between January 2016 to June 2017, 60 patients with acute bleeding peptic ulcers were recruited via both the Gastroenterology Division, Internal Medicine department and the Tropical Medicine department, Zagazig university hospitals, they underwent endoscopic intervention using either injection therapy only with diluted adrenaline 1/10000 (Group I, n20) or Argon plasma coagulation (Group II,n20) or combination therapy using both (Group III,n20), 34 of the enrolled patients were male $(56.7 \%)$ and 26 were females $(43.3 \%)$ with age mean \pm SD $(42.32 \pm 16.39)$.

Past history taking from patients enrolled in the study revealed that 31 patients $(51.7 \%)$ were having history on NSAIDS intake and only 9 patients from all groups $(15 \%)$ had a history of previous peptic ulcer and 16 patients $(26.7 \%)$ were having other comorbidities. Table (1), upon comparing studied population in all groups as regard (age, sex, history of NSAIDs intake, history of peptic ulcer and associated comorbidities there was no significant difference ( $\mathrm{P} \geq 0.05)$ Table (2).

Regarding the location of ulcers, 36 cases (60\%) involved the duodenum and 24 cases (40\%) involved the stomach. Ulcer types were divided into spurting (n10) (16.7\%), oozing (n17) (28.3\%), ulcer with visible vessel (n16)(26.7\%), and ulcer with adherent clot (n17) (28.3\%), Table (3), there was no statistically significant difference $(\mathrm{P} \geq 0.05)$ between all the studied groups as regards endoscopic findings, Table (4).

Regarding the outcome after endoscopic treatment, Initial hemostasis was achieved in 38 patients $(63.3 \%)$ of total, 10 patients $(50 \%)$ of those treated with adrenaline injection (group I), 11 patients $(55 \%)$ of those treated using argon plasma coagulation (group II) and 17 patients
$(85 \%)$ of those who were subjected to both modalities (group III) with statistically significant difference in favor of group III $(p<0.05)$, Table (5) and Figure (1).

The incidence of rebleeding was found to be 11 patients $(55 \%)$ and 12 patients $(60 \%)$ in groups I and II, respectively, on the other hand, it was found to be less frequent (4 patients, 20\%) in group III who received both therapies with a significant difference between group III and the other two groups $(\mathrm{p}<0.05)$, Table (5) and Figure (2).

Regarding permanent hemostasis, it was achieved in 17 patients $(85 \%)$ of group III who received both treatment options and 10 patients $(50 \%)$ of group I treated with only adrenaline injection and 9 patients (45\%) of group II treated using argon plasma coagulation with a significant difference $(\mathrm{P}<0.05)$ in favor of group III, Table (5) and Figure (3).

Results showed that the surgical intervention was needed in 9 patients of the total (4 in group I, 3 in group II and only 2 in group III), with the nonsignificant difference between studied groups $(\mathrm{P} \geq 0.05)$.

Regarding admission days needed for patients it was found to be significantly less in patients of group III (Mean \pm SD $6.65 \pm 2.06$ ) as compared with group I (8.5 \pm 3.35$)$ and group II (9.5 \pm 3.14$)$, and a significant difference $(\mathrm{P}<0.05)$ in favor of group III, Table (5) and Figure (4).

Six deaths occurred in patients with uncontrolled bleeding ( 3 group I, 2 group II and 1 group III) and it was statistically nonsignificant between the studied groups $(\mathrm{P} \geq 0.05)$, Table (5). No post procedural side effects happened in the studied groups. 
Table (1): Baseline demographic data and history obtained from the studied population

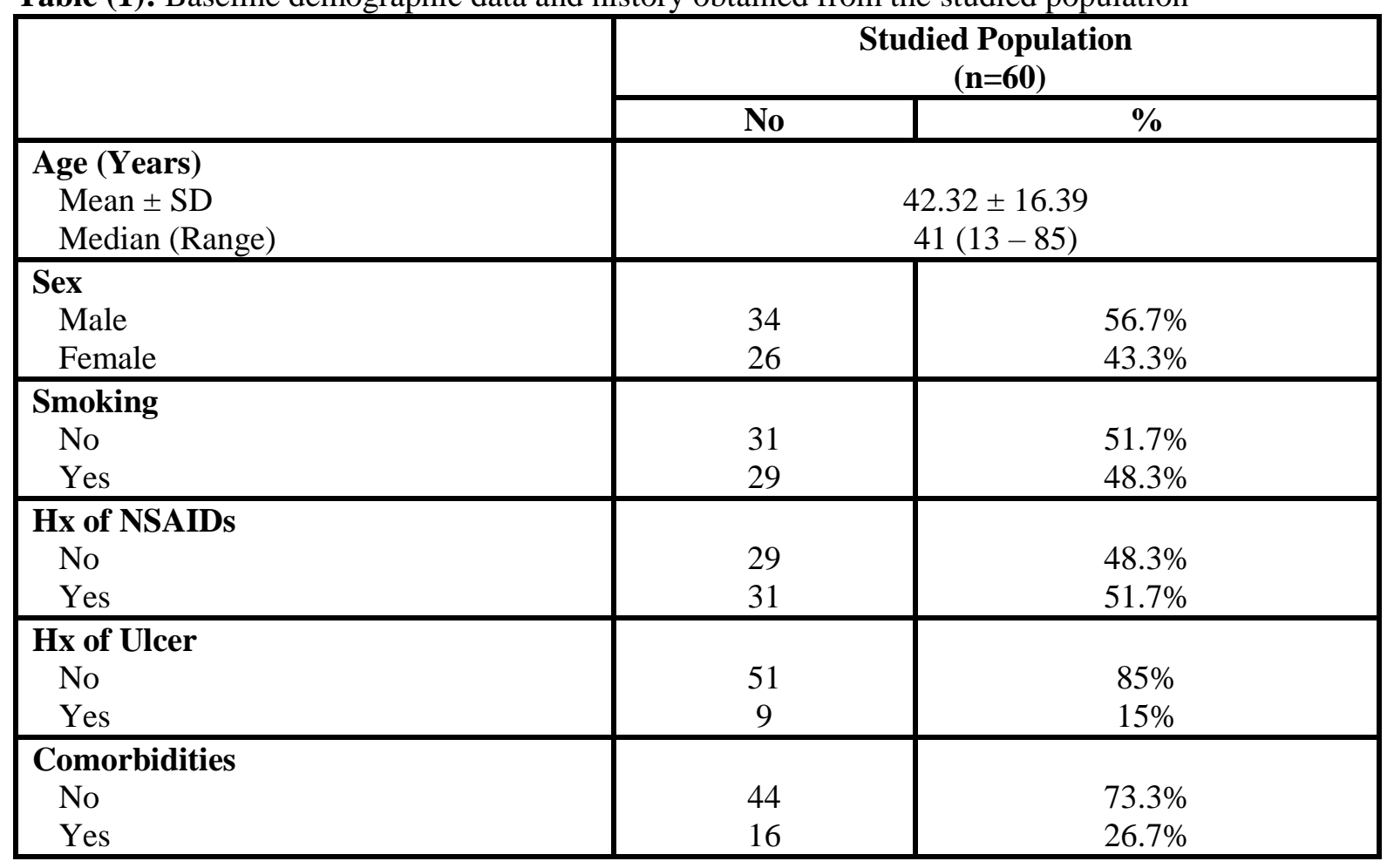

Table (2): Comparison of Demographic data between the studied groups

\begin{tabular}{|c|c|c|c|c|c|c|c|}
\hline & Adren & njection & Arg & asma & Dua & $\begin{array}{l}\text { erapy } \\
\text { 20) }\end{array}$ & $\mathbf{P}$ \\
\hline & No & $\%$ & No & $\%$ & No & $\%$ & \\
\hline $\begin{array}{l}\text { Age (Years) } \\
\text { Mean } \pm \text { SD } \\
\text { Median (Range) } \\
\end{array}$ & & $\begin{array}{r}7.48 \\
-85) \\
\end{array}$ & & $\begin{array}{l}15.88 \\
74)\end{array}$ & $\begin{array}{r}42 . \\
41 \\
\end{array}$ & $\begin{array}{c}16.57 \\
-70)\end{array}$ & 0.95 \\
\hline $\begin{array}{l}\text { Sex } \\
\text { Male } \\
\text { Female }\end{array}$ & $\begin{array}{c}13 \\
7\end{array}$ & $\begin{array}{l}65 \% \\
35 \%\end{array}$ & $\begin{array}{l}10 \\
10\end{array}$ & $\begin{array}{l}50 \% \\
50 \%\end{array}$ & $\begin{array}{c}11 \\
9\end{array}$ & $\begin{array}{l}55 \% \\
45 \%\end{array}$ & 0.62 \\
\hline $\begin{array}{l}\text { Smoking Status } \\
\text { Non-Smoker } \\
\text { Smoker } \\
\end{array}$ & $\begin{array}{c}9 \\
11 \\
\end{array}$ & $\begin{array}{l}45 \% \\
55 \%\end{array}$ & $\begin{array}{c}11 \\
9 \\
\end{array}$ & $\begin{array}{l}55 \% \\
45 \% \\
\end{array}$ & $\begin{array}{c}11 \\
9 \\
\end{array}$ & $\begin{array}{l}55 \% \\
45 \%\end{array}$ & 0.77 \\
\hline $\begin{array}{l}\text { Hx of NSAIDs } \\
\text { No } \\
\text { Yes }\end{array}$ & $\begin{array}{c}8 \\
12\end{array}$ & $\begin{array}{l}40 \% \\
60 \%\end{array}$ & $\begin{array}{c}9 \\
11\end{array}$ & $\begin{array}{l}45 \% \\
55 \%\end{array}$ & $\begin{array}{c}12 \\
8 \\
\end{array}$ & $\begin{array}{l}60 \% \\
40 \%\end{array}$ & 0.42 \\
\hline $\begin{array}{l}\text { Hx of Ulcer } \\
\text { No } \\
\text { Yes }\end{array}$ & $\begin{array}{c}16 \\
4\end{array}$ & $\begin{array}{l}80 \% \\
20 \%\end{array}$ & $\begin{array}{c}17 \\
3\end{array}$ & $\begin{array}{l}85 \% \\
15 \%\end{array}$ & $\begin{array}{c}18 \\
2\end{array}$ & $\begin{array}{l}90 \% \\
10 \%\end{array}$ & 0.68 \\
\hline $\begin{array}{l}\text { Comorbidities } \\
\text { No } \\
\text { Yes } \\
\end{array}$ & $\begin{array}{c}13 \\
7 \\
\end{array}$ & $\begin{array}{l}65 \% \\
35 \% \\
\end{array}$ & $\begin{array}{c}15 \\
5 \\
\end{array}$ & $\begin{array}{l}75 \% \\
25 \% \\
\end{array}$ & $\begin{array}{c}16 \\
4 \\
\end{array}$ & $\begin{array}{l}80 \% \\
20 \% \\
\end{array}$ & 0.55 \\
\hline $\begin{array}{l}\text { Shock } \\
\text { No } \\
\text { Yes }\end{array}$ & $\begin{array}{c}18 \\
2\end{array}$ & $\begin{array}{l}90 \% \\
10 \%\end{array}$ & $\begin{array}{c}18 \\
2\end{array}$ & $\begin{array}{l}90 \% \\
10 \%\end{array}$ & $\begin{array}{c}19 \\
1\end{array}$ & $\begin{array}{c}95 \% \\
5 \%\end{array}$ & 0.80 \\
\hline
\end{tabular}

There were no statistical differences between groups. 
Table (3): Endoscopic findings of the studied population

\begin{tabular}{|l|c|c|}
\hline \multirow{2}{*}{} & \multicolumn{2}{|c|}{$\begin{array}{c}\text { Studied Population } \\
\text { (n=60) }\end{array}$} \\
\cline { 2 - 3 } & No & \% \\
\hline Site of PUD & 36 & $60 \%$ \\
DU & 24 & $40 \%$ \\
GU & & \\
\hline Forrest classification & 10 & $16.7 \%$ \\
Spurting & 17 & $28.3 \%$ \\
Oozing & 16 & $26.7 \%$ \\
Visible vessel & 17 & $28.3 \%$ \\
Adherent clot & \multicolumn{2}{|}{} \\
\hline
\end{tabular}

Table (4) Comparison of endoscopic findings between the studied groups

\begin{tabular}{|c|c|c|c|c|c|c|c|}
\hline & \multicolumn{2}{|c|}{$\begin{array}{c}\text { Adrenaline injection } \\
(\mathrm{n}=\mathbf{2 0})\end{array}$} & \multicolumn{2}{|c|}{$\begin{array}{c}\text { Argon Plasma } \\
(\mathrm{n}=\mathbf{2 0})\end{array}$} & \multicolumn{2}{|c|}{$\begin{array}{c}\text { Dual Therapy } \\
(\mathbf{n}=20)\end{array}$} & \multirow[t]{2}{*}{$\mathbf{P}$} \\
\hline & No & $\%$ & No & $\%$ & No & $\%$ & \\
\hline $\begin{array}{l}\text { PUD } \\
\text { DU } \\
\text { GU }\end{array}$ & $\begin{array}{c}11 \\
9\end{array}$ & $\begin{array}{l}55 \% \\
45 \%\end{array}$ & $\begin{array}{c}12 \\
8\end{array}$ & $\begin{array}{l}60 \% \\
40 \%\end{array}$ & $\begin{array}{c}13 \\
7\end{array}$ & $\begin{array}{l}65 \% \\
35 \%\end{array}$ & 0.81 \\
\hline $\begin{array}{l}\text { Spurting } \\
\text { No } \\
\text { Yes } \\
\end{array}$ & $\begin{array}{c}17 \\
3 \\
\end{array}$ & $\begin{array}{l}85 \% \\
15 \% \\
\end{array}$ & $\begin{array}{c}16 \\
4 \\
\end{array}$ & $\begin{array}{l}80 \% \\
20 \% \\
\end{array}$ & $\begin{array}{c}17 \\
3 \\
\end{array}$ & $\begin{array}{l}85 \% \\
15 \% \\
\end{array}$ & 0.89 \\
\hline $\begin{array}{l}\text { Oozing } \\
\text { No } \\
\text { Yes } \\
\end{array}$ & $\begin{array}{c}13 \\
7\end{array}$ & $\begin{array}{l}65 \% \\
35 \% \\
\end{array}$ & $\begin{array}{c}16 \\
4\end{array}$ & $\begin{array}{l}80 \% \\
20 \%\end{array}$ & $\begin{array}{c}14 \\
6 \\
\end{array}$ & $\begin{array}{l}70 \% \\
30 \%\end{array}$ & 0.56 \\
\hline $\begin{array}{l}\text { Visible } \\
\text { vessel } \\
\text { No } \\
\text { Yes }\end{array}$ & $\begin{array}{c}16 \\
4\end{array}$ & $\begin{array}{l}80 \% \\
20 \%\end{array}$ & $\begin{array}{c}14 \\
6\end{array}$ & $\begin{array}{l}70 \% \\
30 \%\end{array}$ & $\begin{array}{c}14 \\
6\end{array}$ & $\begin{array}{l}70 \% \\
30 \%\end{array}$ & 0.71 \\
\hline $\begin{array}{l}\text { Adherent } \\
\text { clot } \\
\text { No } \\
\text { Yes }\end{array}$ & $\begin{array}{c}14 \\
6\end{array}$ & $\begin{array}{l}70 \% \\
30 \%\end{array}$ & $\begin{array}{c}14 \\
6\end{array}$ & $\begin{array}{l}70 \% \\
30 \%\end{array}$ & $\begin{array}{c}15 \\
5\end{array}$ & $\begin{array}{l}75 \% \\
25 \%\end{array}$ & 0.92 \\
\hline
\end{tabular}

There were no statistical differences between groups. 
Table (5): Comparison of Outcome after endoscopic treatment

\begin{tabular}{|c|c|c|c|c|c|c|c|}
\hline & \multicolumn{2}{|c|}{$\begin{array}{c}\text { Adrenaline } \\
\text { injection } \\
(n=20)\end{array}$} & \multicolumn{2}{|c|}{$\begin{array}{l}\text { Argon Plasma } \\
\qquad(\mathbf{n}=\mathbf{2 0})\end{array}$} & \multicolumn{2}{|c|}{$\begin{array}{l}\text { Dual Therapy } \\
\qquad(\mathbf{n}=\mathbf{2 0})\end{array}$} & \multirow[t]{2}{*}{$\mathbf{P}$} \\
\hline & No & $\%$ & No & $\%$ & No & $\%$ & \\
\hline $\begin{array}{l}\text { Initial } \\
\text { hemostasis } \\
\text { No } \\
\text { Yes }\end{array}$ & $\begin{array}{l}10 \\
10\end{array}$ & $\begin{array}{l}50 \% \\
50 \%\end{array}$ & $\begin{array}{c}9 \\
11\end{array}$ & $\begin{array}{l}45 \% \\
55 \%\end{array}$ & $\begin{array}{c}3 \\
17\end{array}$ & $\begin{array}{l}15 \% \\
85 \%\end{array}$ & $0.045 *$ \\
\hline $\begin{array}{l}\text { Perm. } \\
\text { Hemostasis } \\
\text { No } \\
\text { Yes }\end{array}$ & $\begin{array}{l}10 \\
10\end{array}$ & $\begin{array}{l}50 \% \\
50 \%\end{array}$ & $\begin{array}{c}11 \\
9\end{array}$ & $\begin{array}{l}55 \% \\
45 \%\end{array}$ & $\begin{array}{c}3 \\
17\end{array}$ & $\begin{array}{l}15 \% \\
85 \%\end{array}$ & 0.019* \\
\hline $\begin{array}{l}\text { Rebleeding } \\
\text { No } \\
\text { Yes } \\
\end{array}$ & $\begin{array}{c}9 \\
11 \\
\end{array}$ & $\begin{array}{l}45 \% \\
55 \% \\
\end{array}$ & $\begin{array}{c}8 \\
12 \\
\end{array}$ & $\begin{array}{l}40 \% \\
60 \% \\
\end{array}$ & $\begin{array}{c}16 \\
4 \\
\end{array}$ & $\begin{array}{l}80 \% \\
20 \% \\
\end{array}$ & $0.021 *$ \\
\hline $\begin{array}{l}\text { Need for } \\
\text { surgery } \\
\text { No } \\
\text { Yes }\end{array}$ & $\begin{array}{c}16 \\
4\end{array}$ & $\begin{array}{l}80 \% \\
20 \%\end{array}$ & $\begin{array}{c}17 \\
3\end{array}$ & $\begin{array}{l}85 \% \\
15 \%\end{array}$ & $\begin{array}{c}18 \\
2\end{array}$ & $\begin{array}{l}90 \% \\
10 \%\end{array}$ & 0.68 \\
\hline $\begin{array}{l}\text { Mortality } \\
\text { No } \\
\text { Yes } \\
\end{array}$ & $\begin{array}{c}17 \\
3 \\
\end{array}$ & $\begin{array}{l}85 \% \\
15 \% \\
\end{array}$ & $\begin{array}{c}18 \\
2 \\
\end{array}$ & $\begin{array}{l}90 \% \\
10 \% \\
\end{array}$ & $\begin{array}{c}19 \\
1 \\
\end{array}$ & $\begin{array}{c}95 \% \\
5 \%\end{array}$ & 0.57 \\
\hline $\begin{array}{l}\text { Admission } \\
\text { (Days) } \\
\text { Mean } \pm \text { SD } \\
\text { Median } \\
\text { (Range) }\end{array}$ & \multicolumn{2}{|c|}{$\begin{array}{c}8.5 \pm 3.35 \\
8.5(3-15)\end{array}$} & \multicolumn{2}{|c|}{$\begin{array}{c}9.5 \pm 3.14 \\
9.5(3-15)\end{array}$} & \multicolumn{2}{|c|}{$\begin{array}{c}6.65 \pm 2.06 \\
6(4-12)\end{array}$} & $0.01 *$ \\
\hline
\end{tabular}

* = Significant

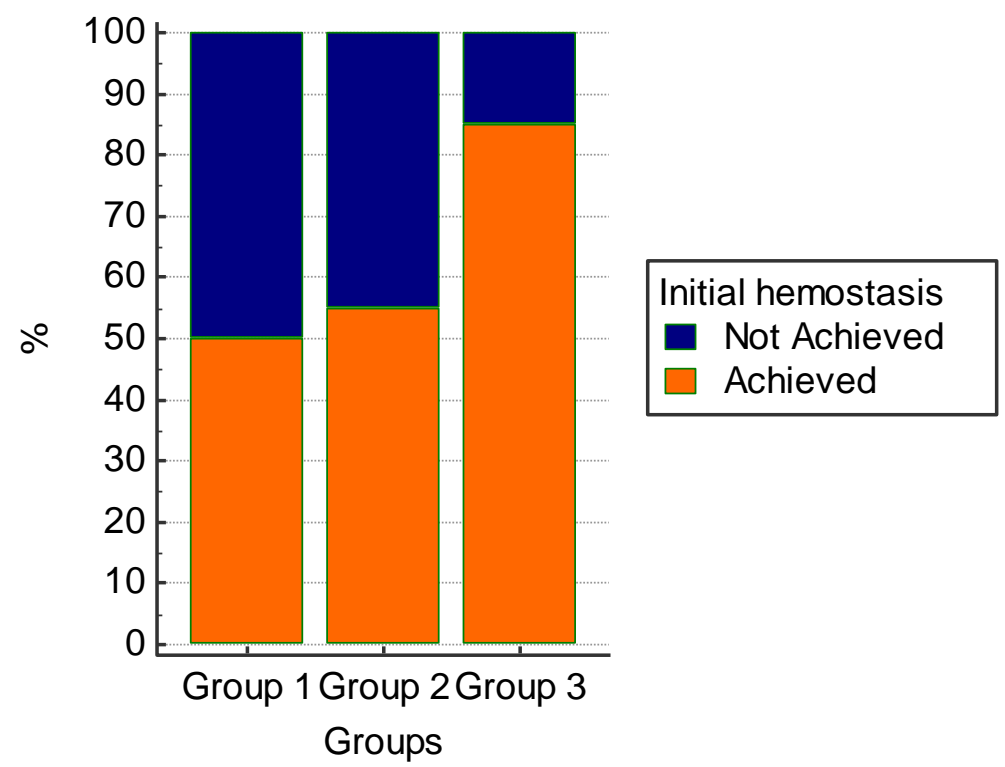

Figure (1): 100\% stacked bar chart showing the distribution of outcome in terms of initial hemostasis in different groups, revealing that the percentage of change achieved in group III is greater than groups I and II 


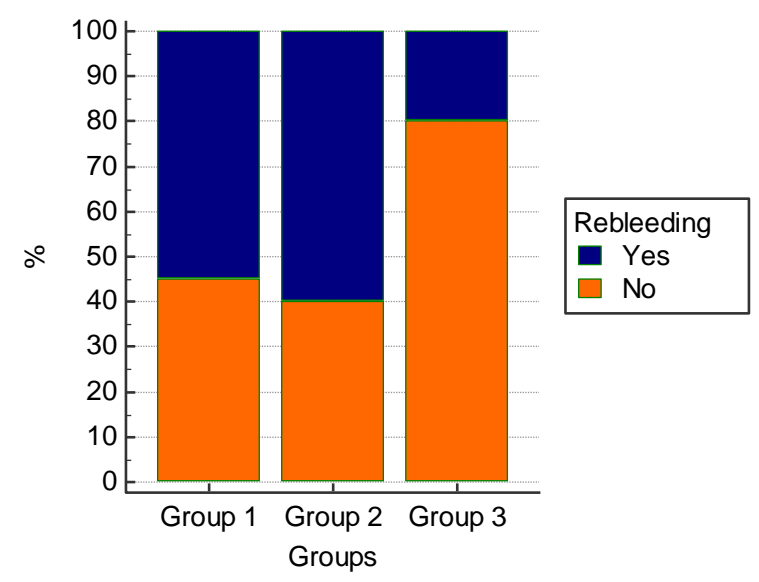

Figure (2): 100\% stacked bar chart showing the distribution of outcome in terms of rebleeding after intervention in different groups, revealing that percentage of rebleeding in group III is less than those in groups I and II.

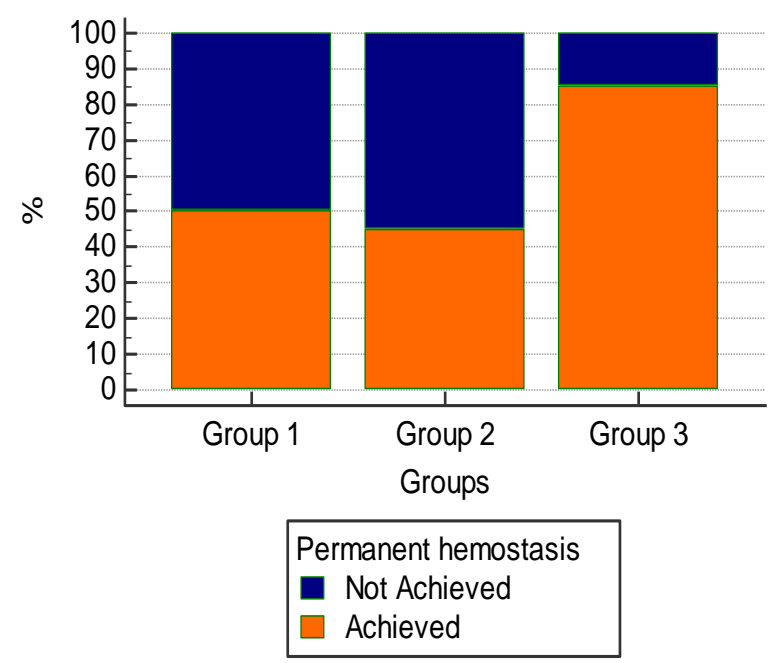

Figure (3): 100\% stacked bar chart showing the distribution of outcome in terms of permanent hemostasis in different groups, revealing that the percentage of change achieved in group III is greater than groups I and II.

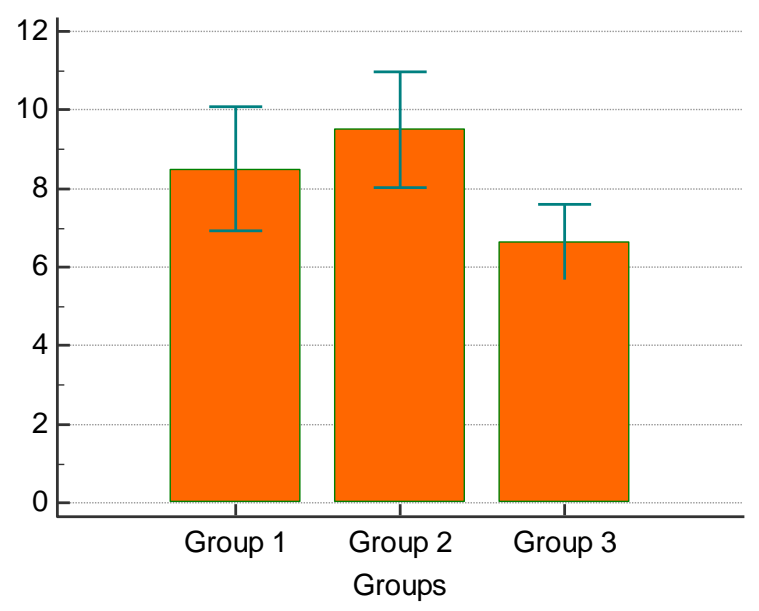

Figure (4): Bar chart denoting the mean duration of admission of different groups with less number of days in group III as compared with other groups. Error bars indicate 95\% CI. 
Table (6): Relative risk of outcome after endoscopic treatment (monotherapy versus dual therapy)

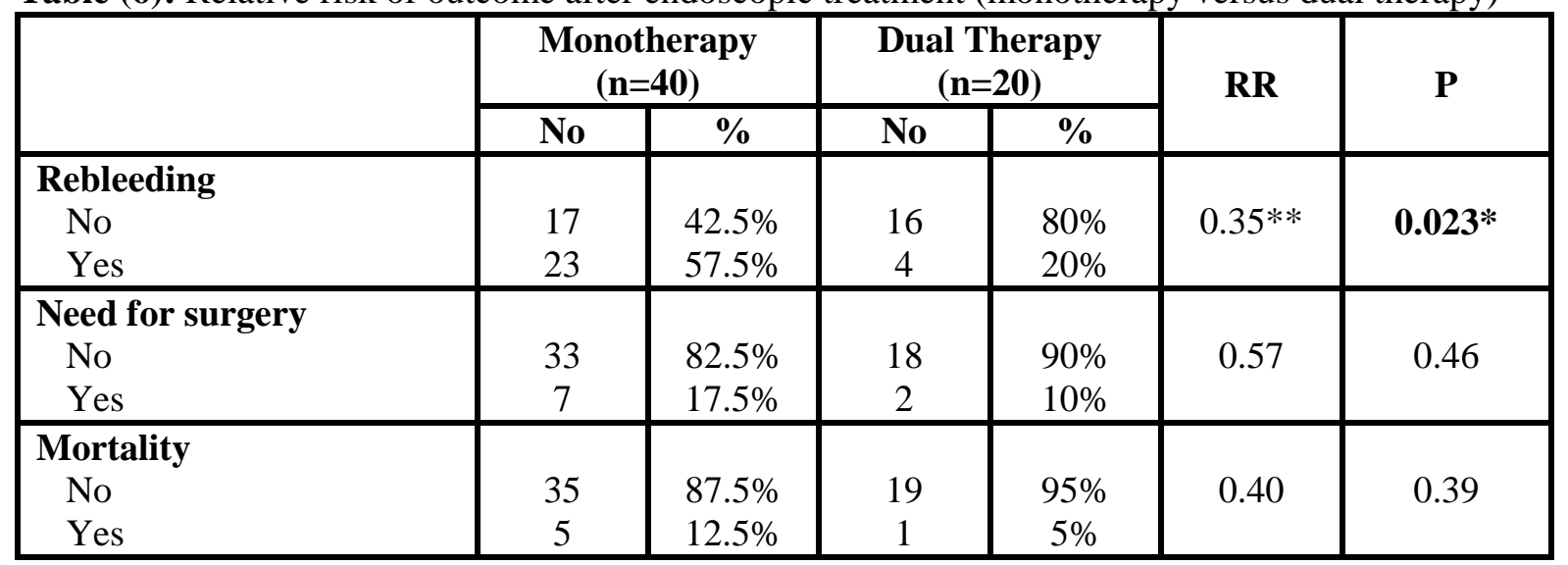

$*$ = Significant

$* *=$ There is $65 \% \mathrm{RR}$ of rebleeding on group exposed to dual therapy compared to monotherapy

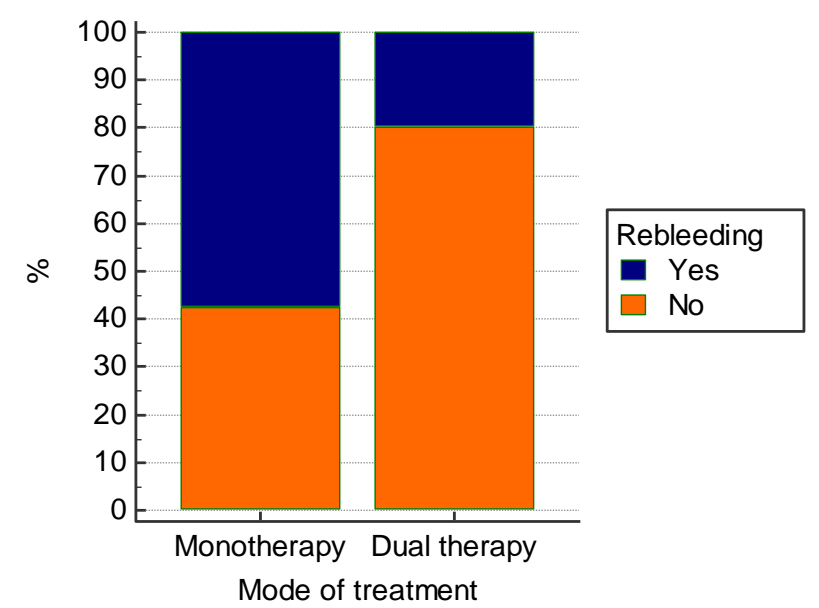

Figure (5): 100\% stacked bar chart comparing distribution of outcome in terms of rebleeding after intervention between group III(dual therapy) on one side and groups I and II as one group (monotherapy) on the other side, revealing that percentage of rebleeding in the dual therapy group is less than those in the monotherapy group

\section{DISCUSSION}

Acute upper gastrointestinal bleeding from peptic ulcer remains an important cause of emergency presentation and hospital admission, and is still associated with significant morbidity, mortality, and healthcare costs, in spite of advances in many aspects of its management [8].

Endoscopic injection therapy using diluted adrenaline for treatment of bleeding peptic ulcers, is the most commonly used among other solutions. Although it can successfully stop the majority of ulcer bleeds, recurrent bleeding still occurs in $10 \%$ to $30 \%$ of cases [11].

Argon plasma coagulation (APC) is a new method that offers controlled, non-contact electro- coagulation. APC has proven to be safe and effective for coagulation of tissue to achieve hemostasis [11].

This study showed that the efficacy of using both adrenaline injection and argon plasma coagulation in controlling and treating acute peptic ulcer bleeding is superior to that of adrenaline injection therapy or argon plasma coagulation alone as regards both Initial and permanent hemostasis, incidence of rebleeding and hospital admission days needed, On the other hand no specific therapeutic option succeeded to prove more effectiveness in need for surgery or mortality rates.

This goes with Wang et al. [2] who found that hemostatic efficacy of APC treatment following 
injection therapy was superior to that of injection therapy alone in preventing rebleeding in patients with bleeding high-risk peptic ulcers but without a difference in hospital admission days[2].

It goes also with Sung et al. [12] who recommended the use of thermocoagulation in high-risk ulcers together with epinephrine injection therapy.

This is also in agreement with Alireza et al. [11] who stated that It is generally accepted that the combination of injection therapy with another method of hemostasis (eg, injection therapy+ heater probe, injection therapy + hemoclips) is superior to injection therapy alone for definitive control of bleeding, especially in high-risk ulcers.

Our study revealed that there was no superior effectiveness for using argon plasma coagulation alone in treating bleeding peptic ulcer when compared with adrenaline injection alone or both as a dual therapy and this goes with Wang et al. [2] who mentioned that guidelines did not mention whether clear evidence existed that APC, a noncontact thermocoagulation, could help treat high-risk bleeding ulcers, and also with Havanond [10] in a systemic review of APC therapy compared with heater probe and sclerosant injection and found no evidence of the superiority of APC to other endoscopic modalities.

Our study found also that when comparing rebleeding rates after intervention between group III (dual therapy) on one side and groups I and II as one group (monotherapy) on the other side, it was clear that rebleeding in the dual therapy group is less than those in the monotherapy group.

This is in agreement with Barkun et al. [13] with the international consensus recommending that injection with diluted epinephrine offers suboptimal hemostatic efficacy and should be combined with another method, and also goes with Marmo et al. [14] who mentioned that Combination therapies are already known to overcome single therapies for high-risk bleeding peptic ulcers.

It goes also with Siau et al. [15] who noticed that dual therapy was better than single therapy in decreasing rebleeding rates, emergency surgery and mortality on acute bleeding peptic ulcer.

In this study there was no post procedural complications or modality related mortality and this goes with Wang et al. [2] who stated that No severe adverse procedure-related event (stricture, obstruction, perforation or bleeding) could be identified in his treatment groups and four deaths occurred in patients with uncontrolled rebleeding.
On the contrary Emara et al. [16] reported that two patients of 50 in the group treated with adrenaline injection developed cardiovascular complications (arrhythmia and ischemic heart attack), whereas none in group treated with autologous blood developed complications.

\section{CONCLUSION}

We have found that using both endoscopic adrenaline injection and Argon plasma coagulation as a dual therapy is highly efficacious and favored in controlling acute peptic ulcer bleeding than either modality alone.

Funding: None.

Conflicts of interest: None.

Ethical approval:Approved .

\section{REFERENCES}

1. Tielleman T, Bujanda D. Epidemiology and risk factors for upper gastrointestinal bleeding. Gastrointest Endosc Clin N Am 2015;25:415 428.

2. Wang H-M, Tsai W-L, Yu H-C, Chan H-H, Chen W-C, Lin K-H et al. Improvement of Short-Term Outcomes for High-Risk Bleeding Peptic Ulcers With Addition of Argon Plasma Coagulation Following Endoscopic Injection Therapy. Medicine Clinical Trial/Experimental Study 2015 ; 94, 32.

3. Al Dhahab H, McNabb-Baltar J, Al-Taweel T, Barkun A. State-of-the-art management of acute bleeding peptic ulcer disease. Saudi J Gastroenterol. 2013;19:195-204.

4. Beales IL: Recent advances in peptic ulcer bleeding. F1000 Med Rep. 2009; 1:pii: 44.

5. Mokhtar M, Bozorgi V, Agah S, Nikkhah M, Faghihi A, Boghratian A, et al. Comparison of Glasgow-Blatchford score and full Rockall score systems to predict clinical outcomes in patients with upper gastrointestinal bleeding. Clin Exp Gastroenterol. 2016; 9: 337-43.

6. Budimir I, Stojsavljevic S, Nikolic M, Kralj D, Biscanin A, Kirigin LS, et al. Bleeding Peptic Ulcer: Epidemiology, Treatment, and Prognosis. SM J Gastroenterol. 2017; 3(1): 1007.

7. Ari Garber and Sunguk Jang. Novel Therapeutic Strategies in the Management of Non-Variceal Upper Gastrointestinal Bleeding Clin Endosc 2016; 49:421-424.

8. Vergara M, Bennett C, Calvet X, Gisbert JP. Epinephrine injection versus epinephrine injection and a second endoscopic method in high-risk 
bleeding ulcers. Cochrane Database Syst Rev. 2014;10: CD005584.

9. Ian Beales. Recent advances in the management of peptic ulcer bleeding F1000 Research 2017, 6(F1000 Faculty Rev):1763 Last updated: 27 SEP 2017.

10. Havanond C, Havanond P. Argon plasma coagulation therapy for acute non-variceal upper gastrointestinal bleeding. Cochrane Database Syst Rev. 2005; 2: CD003791.

11. Alireza S, Mohammad S, Mohammad S, Eshraghian A, Eghbali H, Mohsen S, et al., Adrenaline injection plus argon plasma coagulation versus adrenaline injection plus hemoclips for treating high-risk bleeding peptic ulcers: A prospective, randomized trial Can J Gastroenterol 2009; 23(10):699-704.

12. Sung JJ, Chan FK, Chen M, Ching JY, Ho KY, Kachintorn U, et al., Asia-Pacific Working Group consensus on non-variceal upper gastrointestinal bleeding. Gut. 2011; 60:1170-1177.
13. Barkun AN, Bardou M, Kuipers EJ, Sung J, Hunt RH, Martel M, et al., International consensus recommendations on the management of patients with nonvariceal upper gastrointestinal bleeding. Ann Intern Med. 2010;152:101-113.

14. Marmo R, Rotondano G, Piscopo R, Bianco MA, D'Angella R, Cipolletta L. Dual therapy versus monotherapy in the endoscopic treatment of highrisk bleeding ulcers: a meta-analysis of controlled trials. Am J Gastroenterol. 2007;102:279-289.

15. Siau K, Chapman W, Sharma N, Tripathi D, Iqbal $\mathrm{T}$ and Bhala N. Management of acute upper gastrointestinal bleeding: an update for the general physician. J R Coll Physicians Edinb 2017; 47: 218-30.

16. Emara MH, Darwiesh EM, Bihery AS and Zaher TI. Endoscopic injection of autologous blood versus diluted epinephrine for control of actively bleeding gastroduodenal ulcers: a randomized-controlled study. Eur J Gastroenterol Hepatol. 2014; 26(11):1267-72 